\title{
The anorectic response to growth hormone in obese rats is associated with increased ketogenesis: A short communication
}

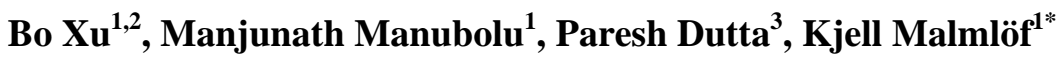 \\ ${ }^{1}$ Department of Anatomy, Physiology, and Biochemistry, Swedish University of Agricultural Sciences, Uppsala, Sweden \\ ${ }^{2}$ Department of Neuroscience, Uppsala University, Uppsala, Sweden \\ ${ }^{3}$ Department of Food Science, Swedish University of Agricultural Sciences, Uppsala, Sweden \\ Email: ${ }^{*}$ Kjell.Malmlof@slu.se
}

Received 26 March 2013; revised 28 April 2013; accepted 8 May 2013

Copyright (C) 2013 Bo Xu et al. This is an open access article distributed under the Creative Commons Attribution License, which permits unrestricted use, distribution, and reproduction in any medium, provided the original work is properly cited.

\begin{abstract}
The purpose of this study was to investigate whether obese rats with a strong anorectic response to growth hormone also showed signs of increased hepatic ketogenesis as reflected in circulating $\beta$-hydroxybutyrate levels. Rats with diet-induced obesity were allocated to one of two groups, receiving either vehicle $(n=7)$ or $4 \mathrm{mg} / \mathrm{kg} / \mathrm{d}$ of growth hormone $(\mathrm{n}=13)$ for 4 days. This latter group was later split into a group of responders $(n=8)$ showing a cumulated reduction of food intake of more than $\mathbf{4} \mathrm{g}$ from base line during the last two days of administrations and a group of non-responders $(n=5)$. The cumulated reduction of food intake from baseline among the responders was $10.8 \pm 1.5 \mathrm{~g}$. The corresponding marginal reductions in the non-responder and vehicle groups were $0.5 \pm$ $3.4 \mathrm{~g}$ and $0.5 \pm 3.7 \mathrm{~g}$, respectively. Growth hormone administration generally increased serum levels of $\beta$ hydroxybutyrate and free fatty acids, compared with vehicle, whereas triglycerides were decreased. Among the responders this effect was statistically significant in all instances whereas the same trend was weaker among non-responders. The main finding of the present study was that the serum $\beta$-hydroxybutyrate levels of $0.76 \pm 0.11 \mathrm{mmol} / \mathrm{l}$ among responders was three times higher than non-responders $(p<0.01)$. In conclusion, the present study suggests that increased hepatic ketogenesis is an important component in the mechanism by which growth hormone inhibits food intake in rats with an obese phenotype. The precise molecular mechanisms, however, remain to be elucidated.
\end{abstract}

\footnotetext{
*Corresponding author.
}

Keywords: Growth Hormone; Lipolysis; Ketogenesis; Food Intake

\section{INTRODUCTION}

Growth hormone $(\mathrm{GH})$ is a powerful stimulator of lipid oxidation [1] and energy expenditure [2]. We have previously shown that the excess of body fat of obese rats is broken down within just 3 weeks during pharmacologic exposure to $\mathrm{GH}$ and that inhibition of food intake is seen in the first phase of this period [3,4]. In our most recent study, the decrease in food intake was associated with decreased hypothalamic galanin [1]. Further investigations of the physiological events associated with the anorectic effect of $\mathrm{GH}$ are principally interesting and motivated. They may provide additional evidence for a link between increased rates of lipid oxidation and inhibition of food intake, and lead to discovery of effective targets for the treatment of obesity. Several authors have suggested that the liver plays a crucial role in this association [5], and that metabolic signals from this organ may affect higher brain centers so that food intake is reduced.

Hepatic $\beta$-oxidation of fatty acids generates $\beta$-hydroxybutyrate which is released into the circulation in proportion to the rate of lipid oxidation. We have noticed that the plasma concentration of $\beta$-hydroxybutyrate shows a relatively high variation during $\mathrm{GH}$ administration and the same is true for food intake. Work with this study, we were interested to investigate whether the group of obese rats with a strong anorectic response to GH also exhibited high levels of circulating $\beta$-hydroxybutyrate response as a marker of increased hepatic fatty acid oxidation and ketogenesis. 


\section{MATERIALS AND METHODS}

\subsection{Experimental Procedures}

The experiments were performed in accordance with the Declaration of Helsinki and were ethically approved by the Regional Ethical Committee for Animal Trials (Uppsala, Sweden). Diet induced obesity (DIO) was established in 12 month old Female Wistar rats (Scanbur AB, Sollentuna, Sweden) by providing free access to high fat diet for three months as previously described [3]. Water was freely available at all times. The rats were subjected to a $12 / 12 \mathrm{~h} \mathrm{light/dark} \mathrm{regime,} \mathrm{and} \mathrm{the} \mathrm{room} \mathrm{temperature}$ was held between $23^{\circ} \mathrm{C}$ and $25^{\circ} \mathrm{C}$. The DIO rats were later randomly allocated to one of two groups, receiving either vehicle $(n=7)$ or GH $(n=13)$. This latter group was later divided in two groups, responders $(\mathrm{n}=8)$ and non-responders $(\mathrm{n}=5)$. The responders showed a cumulated reduction of food intake, from baseline, of more than $4 \mathrm{~g}$ during the last two days of the experiment (See Figure 1), whereas the response in non-responders $(n=5)$ was less than this level. The food intake during the day before first injection served as baseline. Administrations of recombinant human GH (Novo Nordisk AS, Bags vaerd, Denmark) were sustained for 4 days at a dose of 2

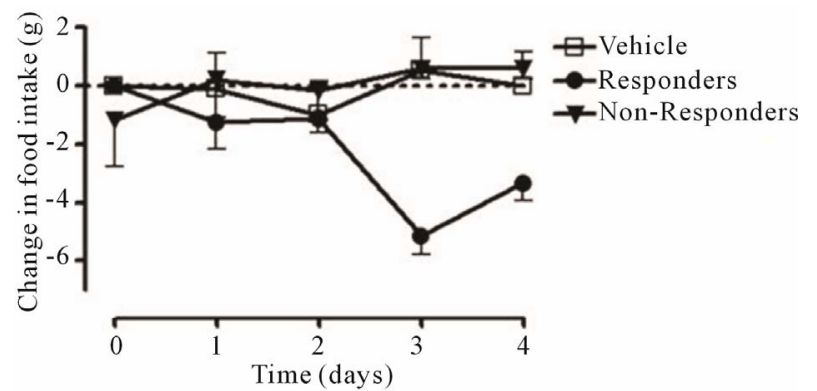

(a)

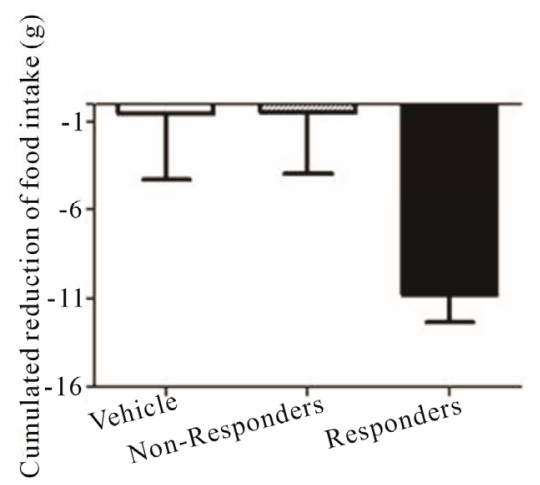

(b)

Figure 1. (a) Effects of GH on food intake in old obese rats responding with a decreased food intake $(\bullet)$, compared with those showing a weak or no response $(\boldsymbol{\nabla})$ and with those receiving vehicle alone ( $\square$ ); (b) Cumulated reduction of food intake from baseline over the 4 day study period among in the same groups as in section A. The results are expressed as means $(n=5-8)$ together with SEM. $\mathrm{mg} / \mathrm{kg}$ given twice daily at 08:00 $\mathrm{h}$ and 18:00 $\mathrm{h}$. Thereafter, animals were killed by decapitation. Decapitation was carried out between 10:00 - 12:00 hours on day 4, and blood serum for analyses of clinical chemistry was prepared by allowing blood to clot before being centrifuged at $5000 \mathrm{rpm}$ during 20 minutes. Serum was stored in $-80^{\circ} \mathrm{C}$ before being analyzed. Biochemical analyses of serum were performed according to standard protocoles at the Department of Clinical Chemistry (Veterinary Faculty, SLU, Uppsala, Sweden).

\subsection{Statistics}

The differences between the groups were evaluated by ANOVA, followed by Bonferroni's post hoc test for multiple comparisons or Kruskal Wallis non parametric test followed by Dunn's multiple comparison test. The data analysis were executed in the GraphPad Prism 5.02 program (GraphPad Software, Inc., La Jolla, CA, USA). Mean values were considered significantly different for $p$ values less than $0.05(\mathrm{p}<0.05)$, and data are presented as means together with standard error (SEM).

\section{RESULTS}

\subsection{Effects of GH on Food Intake}

Over the 4 day study period, the cumulated reduction of food intake from baseline among the responders was $10.8 \pm 1.5 \mathrm{~g}$ (Figures 1(a) and (b)). The corresponding marginal reductions were $0.5 \pm 3.4 \mathrm{~g}$ and $0.5 \pm 3.7 \mathrm{~g}$ for the non-responder and vehicle groups, respectively. Since the rats in the responder and non-responder groups were purposely selected, no statistical test for difference in food intake was performed on these groups.

\subsection{Effects of GH on Plasma Lipid Metabolites in Obese Animals}

GH administration generally increased circulating levels of $\beta$-hydroxybutyrate (BHB), and non-esterified fatty acids (NEFA) whereas triacylglycerol was decreased (Table 1). Among the responders this effect was statistically significant in all instances whereas the same trend was weaker and not always statistically significant among non-responders. However, the main finding in this work was that the increase in $\beta$-hydroxybutyrate among responders was not only significantly different from vehicle rats but also strikingly different $(p<0.01)$ compared with the non-responders (Table 1).

\section{DISCUSSION}

The data generated in the present work shows that animals with a strong anorectic response to $\mathrm{GH}$ also have significantly higher levels of $\beta$-hydroxybutyrate than 
Table 1. Serum lipid metabolites in 12-month-old obese rats responding to $\mathrm{GH}(4 \mathrm{mg} / \mathrm{kg} / \mathrm{d})$ with a decreased food intake, compared with non-responders and with those receiving vehicle alone. Results are expressed as means (SEM).

\begin{tabular}{|c|c|c|c|c|}
\hline & & $\beta$-hydroxybutyrate & Triglycerides & ree Fatty acids \\
\hline Groups & $\mathrm{n}$ & $\mathrm{mmol} / \mathrm{l}$ & $\mathrm{mmol} / \mathrm{l}$ & $\mathrm{mmol} / \mathrm{l}$ \\
\hline Vehicle & 7 & $0.10^{\mathrm{a}}(0.01)$ & $4.2^{\mathrm{a}}(0.90)$ & $0.46^{\mathrm{a}}(0.04)$ \\
\hline$\underset{\text { non-responders }}{\mathrm{GH}}$ & 5 & $0.24^{\mathrm{b}}(0.05)$ & $2.0^{\mathrm{ab}}(0.13)$ & $0.50^{\mathrm{ab}}(0.05)$ \\
\hline GH responders & 8 & $0.76^{c^{*}}(0.11)$ & $1.7^{\mathrm{b}}(0.18)$ & $0.61^{\mathrm{b}}(0.03)$ \\
\hline
\end{tabular}

have animals showing a weaker response. This novel finding is consistent with the previously proposed idea that there is a close connection between increased peripheral fatty acid oxidation and reduced food intake [6] since $\beta$-hydroxybutyrate is a well-established metabolic marker of hepatic oxidation of fatty acids. Thus, our data show that in rats where GH produces a strong stimulation of hepatic lipid oxidation and ketogenesis, food intake is also significantly reduced, and that the opposite is true in animals with a more modest stimulation of hepatic lipid oxidation. This does not, however, automatically mean that it is $\beta$-hydroxybutyrate that in itself constitutes the key signal from the periphery acting on the brain to decrease food intake. In fact, previous trials to demonstrate a direct effect of $\beta$-hydroxybutyrate have generated inconsistent results $[7,8]$ whereas inhibition of fatty acid oxidation has shown more robust results, namely stimulation of food intake [9]. For these reasons it seems reasonable to conclude that circulating $\beta$-hydroxybutyrate may not be the key message from fatty acid oxidation that influences food intake [10]. This conclusion is supported by a recent uncontrolled pilot study from our lab (data not shown) where obese rats received a massive per oral doses of $30 \mathrm{mmol} / \mathrm{kg} /$ day of D-L- $\beta$-hydroxybutyrate for 4 days. No evidence of reduced food intake could be observed in that study; instead food intake was unchanged or slightly elevated throughout the study, compared with baseline values. There are thus strong reasons to believe that it is some unknown factor in the process of hepatic ketogenesis that constitutes the link between increase lipid oxidation and suppression of appetite.

In conclusion, the present study suggests that increased hepatic fatty acid oxidation and associated ketogenesis is an important component in the mechanism by which GH inhibits food intake in rats with an obese phenotype. The precise molecular mechanisms, however, remain to be elucidated.

\section{ACKNOWLEDGEMENTS}

This work was supported by a grant from the Faculty of Veterinary Medicine and Animal Science, SLU, Uppsala and the human Growth hormone was a generous gift from Dr Thygesen, Novo Nordisk, Malov, Denmark.

\section{REFERENCES}

[1] Malmlof, K., Fledelius, C., Johansen, T. and Theodorsson, E. (2012) The anorectic response to growth hormone in obese rats is associated with an increased rate of lipid oxidation and decreased hypothalamic galanin. Physiology and Behavior, 102, 459-465. doi:10.1016/i.physbeh.2010.12.012

[2] Stenlof, K., Johansson, J.-O., Lonn, L., Sjostrom, L. and Bengtsson, B.-A. (1997) Diurnal variations in twenty-fourhour energy expenditure during growth hormone treatment of adults with pituitary deficiency. Journal of Clinical Endocrinology and Metabolism, 82, 1255-1260. doi:10.1210/jc.82.4.1255

[3] Malmlof, K., Din, N., Johansen, T. and Pedersen, S.B. (2002) Growth hormone affects both adiposity and voluntary food intake in old and obese female rats. European Journal of Endocrinology, 146, 121-128. doi:10.1530/eje.0.1460121

[4] Malmlof, K. and Johansen, T. (2003) Growth hormonemediated breakdown of body fat: Insulin and leptin responses to $\mathrm{GH}$ are modulated by diet composition and caloric intake in old rats. Hormone and Metabolic Research, 35, 236-242. doi:10.1055/s-2003-39480

[5] Kahler, A., Zimmermann, M. and Langhans, W. (1999) Suppression of hepatic fatty acid oxidation and food intake in men. Nutrition, 15, 819-828. doi:10.1016/S0899-9007(99)00212-9

[6] Scharrer, E. and Langhans, W. (1986) Control of foodintake by fatty acids oxidation. American Journal of Physiology, 250, 1003-1006.

[7] Fisler, J.S., Egawa, M. and Bray, G.A. (1995) Peripheral 3-hydroxybutyrate and food-intake in a model dietary-fat induced obesity - Effect of vagotomy. Physiology and Behavior, 58, 1-7. doi:10.1016/0031-9384(94)00376-G

[8] Langhans, W., Wiesenreiter, F. and Scharrer, E. (1983) Different effects of subcutaneous D,L-3-hydroxybutyrate and acetoacetate injections of food-intake in rats. Physiology and Behavior, 31, 483-486. doi:10.1016/0031-9384(83)90070-7

[9] Brandt, K., Arnold, M., Geary, N., Langhans, W. and Leonhardt, M. (2007) Vagal afferents mediate the feeding response to mercaptoacetate but not to the beta (3) adrenergic receptor agonist CL 316,243. Neuroscience Letters, 411, 104-107. doi:10.1016/i.neulet.2006.10.034

[10] Scharrer, E. (1999) Control of food intake by fatty acid oxidation and ketogenesis. Nutrition, 15, 704-714. doi:10.1016/S0899-9007(99)00125-2 